\title{
Carta de Leo Löwental a Jürgen Habermas.*
}

$Q^{\text {uerido Jürgen: }}$

Estar presente en la lista de felicitaciones me es absolutamente necesario si bien, al mismo tiempo, en mis circunstancias actuales no me encuentro dispuesto a ofrecer una contribución adecuada. Espero que, como interlocutor de una comunicación emancipada, tanto tú como los editores acepten esta contribución realizada en forma de carta.

Como el último del grupo fundador de la Teoría Crítica me llena de orgullosa satisfacción que la figura más destacada de la segunda generación no sea un epígono, como con frecuencia es el caso de los sucesores de las escuelas filosóficas o de otras escuelas científicas. Me dirijo al filósofo y teórico social que se ha hecho de una posición autónoma pese al compromiso con sus mentores de cuyas "aberraciones fundamentales" con respecto a la "vieja escuela", como tú sabes, no siempre tomé parte. Al mismo tiempo, si fuera aún adecuado ubicarte como heredero de la Teoría Crítica "clásica" me parecería, por supuesto, que las convicciones de trasfondo de la vieja Escuela de Frankfurt en tu pensamiento tienen un eco lejano en relación con una forma de pensar propia, nueva y heterodoxa.

"La carta que aquí se presenta forma parte de un conjunto de "excursos" compilados por Axel Honneth, Thomas McCarthy, Claus Offe y Albrecht Wellmer en ocasión del 60 Aniversario de Jürgen Habermas: Zwischenbetrachtugen im Prosses der Aufklärung (Exćursos en el proceso de la Ilustración). Este libro fue recientemente publicado en Alemania Federal por la editorial Suhrkamp. El texto está dedicado a todos los filósofos, sociólogos y teóricos de la modernidad, así como a los intelectuales de un país que, amenazado siempre por la contra-ilustración, no han dejado de defender las posiciones de un proyecto sobre el cual puede observarse hoy que ni su abandono ni la conclusión del sentido de sus perspectivas serían su posible terminación. (Traducción y notas de Blanca Solares, candidata al doctorado por la Universidad de Frankfurt.) 
114

Formulado de manera más exacta, quiero decir con esta observación de una vez y en principio que no me parece que compartas el melancólico escepticismo tardío de Adorno y Horkheimer en relación con una supresión realizable de la miseria social. Pese a todas tus protestas contra el modelo histórico-filosófico y tu prevención, que no es desatención, con respecto a un límite conceptual utópico, percibo sin embargo en tu interpretación del presente político una motivación utópica -si bien por lo demás distinta. De forma aún más concreta que mi propia generación, no te has satisfecho con consolidar teóricamente el concepto crítico, sino que has hecho de la praxis política cambiante, que reclama la crítica teórica, programa de tu reflexión y de tu personalidad pública. Dos ejemplos que son más que ejemplos: tu sensibilidad frente la desastre nacional-socialista y sus continuidades, con frecuencia sólo legeramente disimuladas en los ámbitos político, moral e intelectual, ha acentuado la claridad en relación con la amenaza que esto representa para la integridad política, moral e intelectual en Alemania Federal. Para nosotros, para quienes el dominio nazi no es sólo una parte de la historia sino un presente vivo que ha permanecido, la seguridad tenaz con la cual detectaste y disecaste de forma imperturbable lo que fueron las sofisticaciones del desastre es digno de admiración e ineludible. Tu intervención encedida en el Debate Histórico ${ }^{1}$ es,

${ }^{1}$ La Historikerstreit o controversia con respecto a la historia alemana surgió en el verano de 1986. Ocasionada por un controvertido artículo escrito por el historiador berlinés Ernst Nolte y publicado en el Frankfurter Allgemeine Zeitung, la Historikerstreit estuvo marcada por una intensidad sin precedentes en la vida pública de Alemania Federal. El debate se transformó de forma rápida en un conflicto intelectual con respecto al significado del pasado nazi en la identidad cultural y política de Alemania. Fue un conflicto que puso en discusión el método histórico, los usos de la historia, su percepción generacional y los límites de la "historización" del Nacional-socialimo. En otros términos, ta así llamada Historikerstreit en relación con el período nazi, ofrece el examen más explícito con respecto a la relación problemática entre conciencia histórica y auto-comprensión de la Alemania contemporánea.

Las intervenciones de Habermas en el debate plantean la necesidad para la izquierda alemana de encontrar una respuesta propia al significado constitutivo de lo que él denomina una "identidad post-convencional": una apropiación crítica de la tradición histórica que como identidad esté vinculada con un nivel de desarrollo político y moral, que haga posible una orientación universal más allá de las perspectivas estrechas y limitadas de una identidad nacional. Critica la retórica neutralista del Movimiento por la Paz y, siguiendo a Karl Jaspers, propone una política moral frente a la postura neoconservadora de una renovación de la identidad nacional y del "relajamiento" con respecto a un pasado centrado en la Stunde Null de 1945. 
para mí, una documentación decisiva de aquello que la Teoría Crítica pensó y hubiera deseado de la teoría y la praxis política.

Esto me trae en segundo lugar el debate sobre la Postmodernidad y el Postestructuralismo. Como sabes, su liturgia apunta en mí particularmente hacia el corazón - dicho de mejor forma, me ataca particularmente contra-coeur. Por tu parte, no has cesado de defender la importancia de la moralidad de la Ilustración -de ninguna forma concluida - ni de la filosofía de la Ilustración en lucha contra las modas, las cuales se confrontan seductoramente con las indiscutibles y ya siempre -desde la perspectiva de la Teoría Críticaestigmatizables debilidades de la Ilustración clásica. En el proceso de este discurso has coadyuvado sin cesar al socavamiento de la arbitrariedad en el establecimiento de sus valores teóricos, morales y políticos, la develación de su "impenetrabilidad" de hecho manipulada. En este sentido, eres el representante más efectivo del proyecto aún actual de la llustración y de sus demandas de competencia comunicativa.

En tu discurso, con motivo de mi 80 aniversario, hablaste de mi "impeturbabilidad eventualmente molesta". Tu imperturbabilidad a mí aún no me ha molestado en absoluto.

Te desea cariñosamente lo mejor, 